\title{
VAGINAL MISOPROSTOL FOR SECOND AND THIRD TRIMESTER LABOUR INDUCTION IN WOMEN WITH INTRAUTERINE FETAL DEATH
}

\author{
El-Gharib MN and Al-Ahwal LM \\ Department of Obstetrics \& Gynaecology, Tanta, Egypt
}

\section{ABSTRACT}

Objectives : To evaluate the effect of repeated vaginal administration of small doses of misoprostol for termination of pregnancy in cases of second and third trimester pregnancies complicated with intra-uterine fetal death (IUFD).

Design: A prospective Clinical Trial.

Setting : Tanta University Hospitals .

Patients : The study was carried out on 40 women during the second and third trimesters of pregnancy complicated with IUFD.

Intervention: All the patients were subjected to history taking, physical examination, Bishop Scoring. Application of $25 \mu \mathrm{g}$ misoprostol (Vagiprost ${ }^{\circledR}$ tablet) in the posterior fornix of the vagina, which will be repeated every 4 hours over 24 hours.

Outcome measures: The primary outcome measure was the success rate, the secondary outcome measure was the induction to delivery time, and third outcome measure was the number of patients requiring augmentation with oxytocin and all complications were recorded.

Results: The mean value of induction contraction interval in cases of 2 nd trimester IUFD (15.3 \pm 5.37 hours) was significantly higher than that in cases of 3rd trimester IUFD ( $8.95 \pm 2.625$ hours). There was a significant negative correlation between gestational age and induction contraction interval as well as induction delivery interval. The success rate was $90 \%$ and $45 \%$ in the third and second trimesters respectivley. Ninety percent of 2 nd trimester cases and $55 \%$ of 3 rd trimester cases required oxytocin augmentation. The mean values of total required dose of misoprostol required for induction wer $120 \pm 28.79 \mu \mathrm{g}$ and $166.3 \pm 7.5 \mu \mathrm{g}$ for the third and second trimesters respectively.

Conclusion: Vagiprost is a very effective drug for termination of pregnancy in cases of IUFD, its effects increase in direct proportion with parity and duration of pregnancy.

Key words: Misoprostol; induction of laboru; intrauterine fetal death.

\section{INTRODUCTION}

Intrauterine foetal death (IUFD) is a common obstetric complication that can lead to serious maternal complications if left to resolve spontaneously ${ }^{(1)}$.

The management of IUFD poses a dilemma. Although a significant number of these patients will spontaneously go into labour within several weeks many do not. Moreove, after the diagnosis, the social pressures and emotional aspects of delivery are usually considerable, and the medical consequences of postponing delivery can be significant. Unfortunately, the drug most commonly used for induction of labour, oxytocin, is frequently ineffective in stimulating the uterus, especially the preterm one. Within the past two decades, prostaglandins (PGs) have provided an alternative method for induction of labour in women with IUFD ${ }^{(2)}$.

Misoprostol (PGE1 analogue) has been widely used for cervical ripening and labour induction in various pregnancy conditions, at different gestational ages and using different routes of administration and dose regimens ${ }^{(3)}$. Although misoprostol is effective and inexpensive, concern has been raised regarding the widespread use of this agent as a primary or adjuvant 
agent for labour induction ${ }^{(4)}$. Inspite of these concerns, a large body of evidence exists that shows that the use of misoprostol for labour induction is highly efficacious and $\operatorname{safe}^{(5)}$.

Despite a campaign by the manufacturer to curtail use of misoprostol in obstetric practice, it has gained widespread acceptance, over the past several years, as both a labour induction and a cervical ripening agent.

Before misoprostol widespread use in the mid 1990s, other PGs such as PGE2 vaginal suppositories and PG F2 $\alpha$ injections were most commonly used for second-trimester pregnancy terminations (STPT). These agents, although also efficacious, are associated with side effects such as severe nausea, vomiting, diarrhca and fever in a high percentage of patients ${ }^{(7)}$.

The aim of this work was: To evaluate the effect of repealed vaginal administration of small doses $(25 \mu \mathrm{g})$ of misoprostol in termination of pregnancy in cases of second and third trimester pregnancies complicated with IUFD.

\section{PATIENTS}

This study included 40 women recruited from Tanta University Hospital, Obstetrics \& Gynaccology department. They were divided into 2 groups:

A. Group (1): included 20 cases of 2 nd trimester pregnancy complicated with IUFD, as documented by ultrasound examination.

B. Group (2): included 20 cases of 3 rd trimester pregnancy complicated with IUFD, as documented by ultrasound examination.

Inclusion criteria :

- IUFD with gestational age $\geq 13$ weeks.

- Absent spontaneous laabour pain.

- Bishop cervical score $<5$.

Exclusion criteria :

- Cases with general contraindications to PGs including: epilepsy, glaucoma, cardiac disease, bronchial asthma, renal or hepatic dysfunction, diabetes and history of hypersensitivity to PGs.

- Cases with local contraindications to PGs including: Grand multiparas, fetal macrosomia, multiple pregnancies, abnormal presentation, previous uterine scar, Bishop score $\geq 5$, PROM, Placenta praevia, Contracted pelvis and Cephalo-pelvic disproportion.

\section{METHODS}

- All cases were subjected to :-

- History taking, clinical examination \& ultrasound examination.

- Counseling the patient \& obtaining written consent.

- Determination of Bishop Score before application of PG.

- Application of $25 \mu \mathrm{g}$ misoprostol (Vagiprost ${ }^{\circledR}$ tablet) in the posterior fornix of the vagina, which will be repeated every 4 hours over 24 hours. The tablet was covered with K-Y gel before insertion.

- Observation of patients over 24 hours, after application of vagiprost tablet, for the following: Vital signs, Onset of the true labour pain, Passage of the liquor, Passage of the fetus.

- Vaginal examination 4 hours after application of vagiprost (unless uterine tonicity occurs) and assessment of Bishop Score A. If Bishop Score A was $<5$ another dose of vagiprost was given and vaginal examination was done after 4 hours to determine Bishop score B. This was repeated till a maximum of 6 doses (i.e. $150 \mu \mathrm{g}$ ) or Bishop Score $\geq$ 5 without efficient regular uterine contractions, in such condition augmentation by oxytocin drip was done 4 hours after last misoprostol dose.

- Recording the total dose of misoprostol administered $\&$ the need for surgical interference to remove the retained placenta.

- Failure of delivery within 24 hours is considered "failed trial", but it's not an indication to stop the trial i.e. the trial will be completed till termination. 
- Observation of patients for 24 hours after delivery.

- Any complications during induction and 24 hours after delivery should be observed \& reported.

\section{RESULTS}

The mean gestational age (GA) in primiparae (P1) and second para (P2) was 25.5 \pm 1.378 weeks, which was significantly higher than that in nullipara (P0) which was $22.67 \pm 2.50$ weeks. The mean GA in third para (P3) and fourth para (P4) was $26.375 \pm 0.74$ weeks. This value was significantly higher than that in P0.

There was no significant difference between the mean of GA in P1\&P2 (25.500土1.378 weeks) and that in P3 \& P4 (26.37 \pm 0.744 weeks).

ANOVA test, comparing the variance between the 3 groups revealed the presence of significant difference $(F=9.37$ and $P<0.01)$.

Table I : Correlation between parity and induction contraction interval, induction delivery interval and with total needed dose of misoprostol (in micrograms), in cases of 2 nd trimester IUFD.

\begin{tabular}{|l|c|c|}
\hline \multicolumn{1}{|c|}{ Spearman correlation } & r & P-Value \\
\hline Parity versus Induction Contraction interval & -0.481 & 0.032 \\
\hline Parity versus Induction Delivery interval & -0.480 & 0.032 \\
\hline Parity versus total needed dose & -0.572 & 0.008 \\
\hline
\end{tabular}

There was a significant negative correlation between parity and induction contraction interval. Also, there was a significant negative correlation between parity and induction delivery interval. Also, there was a highly significant negative correlation between parity and total needed dose of misoprostol.

Table II : Correlation between gestational age (GA) in weeks and induction contraction interval (in hours), induction delivery interval and total needed dose of misoprostol (in micrograms), in cases of 2 nd trimester IUFD.

\begin{tabular}{|l|c|c|}
\hline \multicolumn{1}{|c|}{ Pearson correlation } & r & P-Value \\
\hline G. Age versus Induction Contraction interval & -0.921 & 0.00 \\
\hline G. Age versus Induction Delivery interval & -0.864 & 0.00 \\
\hline G. Age versus total needed dose & -0.842 & 0.00 \\
\hline
\end{tabular}

There is a highly significant negative correlation between gestational age and induction contraction interval. Also, there was a highly significant negative correlation between gestational age and induction delivery interval. Also, there was a highly significant negative correlation between gestational age and total needed dose of misoprostol.

Table III : The mean values of "induction contraciton interval" in relation to the "parity" in women with 2nd trimester IUFD.

\begin{tabular}{|l|l|c|c|c|}
\hline \multicolumn{2}{|c|}{ Induction Contraction interval } & \multicolumn{3}{c|}{ Parity in 2nd trimester } \\
\cline { 2 - 5 } & 0 & $1-2$ & $3-4$ \\
\hline Mean \pm SD & $20.33 \pm 5.39$ & $14.00 \pm 3.52$ & $12.50 \pm 4.07$ \\
\hline t-Test & $\mathrm{Tl}\left(0 \mathrm{~V}_{\mathrm{s}} \mathrm{d}-2\right)$ & $\mathrm{T} 2(0 \mathrm{Vs} 3-4)$ & $\mathrm{T} 3\left(1-2 \mathrm{~V}_{\mathrm{S}} 3-4\right)$ \\
\hline $\mathrm{T}$ & $\mathrm{F}$ & 2.41 & 2.98 & 0.74 \\
\hline \multirow{2}{*}{ ANOVA } & P-value & & 5.91 & 0.011 \\
\hline
\end{tabular}


Table IV : The mean values of "induction delivery interval" in relation to the "parity" in cases of 2 nd trimester IUFD.

\begin{tabular}{|c|c|c|c|c|}
\hline \multirow{2}{*}{\multicolumn{2}{|c|}{ Induction Delivery interval }} & \multicolumn{3}{|c|}{ Parity in 2nd trimester } \\
\hline & & 0 & $1-2$ & $3-4$ \\
\hline \multicolumn{2}{|c|}{ Mean \pm SD } & $36.17 \pm 7.22$ & $26.33 \pm 7.34$ & $25.63 \pm 3.81$ \\
\hline \multicolumn{2}{|l|}{ t-Test } & $\mathrm{T} 1(0 \mathrm{Vs} 1-2)$ & $T 2(0$ Vs 3-4) & $T 3(1-2$ Vs $3-4)$ \\
\hline \multicolumn{2}{|l|}{$T$} & 2.34 & 3.25 & 0.22 \\
\hline \multirow{2}{*}{ ANOVA } & $F$ & \multicolumn{2}{|l|}{5.94} & \\
\hline & P-value & \multicolumn{2}{|l|}{0.011} & \\
\hline
\end{tabular}

Table V : The mean values of total required dose of misoprostol (in micrograms) in relation to the parity in cases of 2 nd trimester IUFD.

\begin{tabular}{|l|l|c|c|c|}
\hline \multirow{2}{*}{ Total dose } & \multicolumn{3}{c|}{ Parity in 2nd trimester } \\
\cline { 2 - 5 } \multicolumn{2}{|c|}{} & $\mathbf{0}$ & $\mathbf{1 - 2}$ & $\mathbf{3 - 4}$ \\
\hline Mean $\pm \mathrm{SD}$ & $212.5 \pm 46.8$ & $175.0 \pm 52.4$ & $137.5 \pm 55.1$ \\
\hline $\mathrm{t}-\mathrm{Tcsi}$ & $\mathrm{T} 1(0 \mathrm{Vs} 1-2)$ & $\mathrm{T} 2(0 \mathrm{Vs} 3-4)$ & $\mathrm{T} 3(1-2 \mathrm{Vs} 3-4)$ \\
\hline $\mathrm{T}$ & 1.31 & 2.75 & 1.3 \\
\hline \multirow{2}{*}{ ANOVA } & F & 3.59 & & \\
\cline { 2 - 5 } & P-valuc & 0.05 & & \\
\hline
\end{tabular}

From table (v), it is cvident that the mean total required dose of misoprostoll in P3\&P4 was significantly lower than that in $P O(P>0.05)$. However, there was no significant difference between the mean of required total dose of misoprostol in $\mathrm{P}:$ \& $\mathrm{P} 2$ and that in $\mathrm{PO}(\mathrm{P}>0.05)$.

Table VI : Correlation between "parity" and "induction contraction interval";induction delivery interval and with total needed dose of misoprostol, in cases of 3rd trimester IUFD.

\begin{tabular}{|l|c|c|}
\hline \multicolumn{1}{|c|}{ Spearman correlation } & $\mathbf{r}$ & P-Value \\
\hline Parily Versus Induction Contraction Interval & -0.895 & 0.001 \\
\hline Parity Versus Induction Delivery Interval & -0.899 & 0.001 \\
\hline Parity Versus Total Necded Dose & -0.654 & 0.002 \\
\hline
\end{tabular}

Table VII : The relation between "gestational age" and "induction contraction interval", induction delivery interval and with total needed dose of misoprostol, in cases of 3rd trimester IUFD.

\begin{tabular}{|l|c|c|}
\hline \multicolumn{1}{|c|}{ Pearson correlation } & r & P-Value \\
\hline G. Age versus Induction Contraction Interval & -0.837 & 0.00 \\
\hline G. Age versus Induction Delivery Interval & -0.752 & 0.00 \\
\hline G. Age versus Total needed dose & -0.727 & 0.00 \\
\hline
\end{tabular}


Table VIII : The mean values of gestational age in relation to parity in cases of 3rd trimeaster IUFD.

\begin{tabular}{|c|c|c|c|c|}
\hline & \multirow{2}{*}{ Gestational Age } & \multicolumn{3}{|c|}{ Parity in 2nd trimester } \\
\hline & & $\mathbf{0}$ & $1-2$ & $3-4$ \\
\hline \multicolumn{2}{|c|}{ Mean $\pm S D$} & $33.20 \pm 2.77$ & $34.40 \pm 2.88$ & $32.300 \pm 1.83$ \\
\hline \multicolumn{2}{|l|}{$\mathrm{t}$-Test } & $T 1\left(0 V_{s} 1-2\right)$ & $\mathrm{T} 2(0 \vee \mathrm{s} 3-4)$ & $\mathrm{T} 3\left(1-2 \mathrm{Vs}_{\mathrm{s}} 3-4\right)$ \\
\hline \multicolumn{2}{|l|}{$T$} & 0.67 & 0.66 & 1.49 \\
\hline \multirow{2}{*}{ ANOVA } & $\mathbf{F}$ & & 1.33 & \\
\hline & P-value & & 0.288 & \\
\hline
\end{tabular}

Table IX : The mean values of induction contraction interval in relation to the parity in cases of 3rd trimester IUFD.

\begin{tabular}{|c|c|c|c|c|}
\hline \multirow{2}{*}{\multicolumn{2}{|c|}{ Induction Contraction interval }} & \multicolumn{3}{|c|}{ Parity in 2nd trimester } \\
\hline & & $\mathbf{0}$ & $1-2$ & $3-4$ \\
\hline \multicolumn{2}{|c|}{ Mean $\pm S D$} & $10.2+1.48$ & $6 \pm 1.32$ & $12 \pm 1.22$ \\
\hline \multicolumn{2}{|l|}{ t-Test } & $\mathrm{T} 2(0 \mathrm{Vs} 3-4)$ & T3 $(1-2$ Vs 3-4) & $\mathrm{T} 1(0 \mathrm{Vs} \mathrm{I}-2)$ \\
\hline \multicolumn{2}{|l|}{$T$} & 7.56 & 4.34 & $2.09 \mathrm{~ns}$ \\
\hline \multirow{2}{*}{ ANOVA } & $\mathrm{F}$ & & 28.11 & \\
\hline & P-value & & $<0.001$ & \\
\hline
\end{tabular}

From table (IX) it is clear that there was no significant difference between the mean value of induction contraction interval in $\mathrm{P} 1 \& \mathrm{P} 2$ and that in $\mathrm{P} 0(\mathrm{P}>0.05)$. The mean value of induction contraction interval in $\mathrm{P} 3 \& \mathrm{P} 4$ was significantly lower than that in $\mathrm{P0}(\mathrm{P}<0.05)$. The mean of induction contraciton interval in $\mathrm{P} 3 \& \mathrm{P} 4$ was significantly lower than that in $\mathrm{P} 1 \& \mathrm{P} 2(\mathrm{P}<0.05)$.

Table $\mathrm{X}$ : The mean values of induction delivery interval in relation to the parity in cases of 3rd trimester IUFD.

\begin{tabular}{|c|c|c|c|c|}
\hline \multirow{2}{*}{\multicolumn{2}{|c|}{ Induction Contraction interval }} & \multicolumn{3}{|c|}{ Parity in 2nd trimester } \\
\hline & & 0 & $1-2$ & $3-4$ \\
\hline \multicolumn{2}{|c|}{ Mean $\pm S D$} & $25.2 \pm 2.17$ & $22.4 \pm 1.52$ & $18.3 \pm 2.41$ \\
\hline \multicolumn{2}{|l|}{ t-Test } & $\mathrm{T} 1(0 \mathrm{Vs} 1-2)$ & $\mathrm{T} 2(0 \mathrm{Vs} 3-4)$ & $\mathrm{T} 3\left(1-2 V_{s} 3-4\right)$ \\
\hline \multicolumn{2}{|l|}{$\mathrm{T}$} & 2.37 & 5.6 & 4.02 \\
\hline \multirow{2}{*}{ ANOVA } & $\mathrm{F}$ & & 18.13 & \\
\hline & P-value & & $<0.001$ & \\
\hline
\end{tabular}

Ftom table $(\mathrm{X})$ we see that the mean value of induction delivery interval in $\mathrm{P} 1$ \& $\mathrm{P} 2$ was significantly lower thant that in $\mathrm{PO}(\mathrm{P}<0.05)$. also the mean value of induction delivery interval in $\mathrm{P} 3^{*} \mathrm{P} 4$ was significantly lower than that in $\mathrm{PO}$ $(\mathrm{P}<0.05)$. The mean induction delivery interval in $\mathrm{P} 3 \& 4$ was significantly lower than that in $\mathrm{P} 1 \& \mathrm{P} 2(\mathrm{P}<0.05)$. 
Table XI : The mean values of total needed dose of misoprostol in micrograms ) in relation to the parity in cases of $3 \mathrm{rd}$ trimester IUFD.

\begin{tabular}{|c|c|c|c|c|}
\hline \multirow{2}{*}{\multicolumn{2}{|c|}{ Induction Contraction interval }} & \multicolumn{3}{|c|}{ Parity in 2nd trimester } \\
\hline & & 0 & $1-2$ & 3.4 \\
\hline \multicolumn{2}{|c|}{ Mean \pm SD } & $155 \pm 20.9$ & $110 \pm 13.7$ & $107.5 \pm 23.7$ \\
\hline \multicolumn{2}{|l|}{ L-Test } & $\mathrm{T} 1(0 \mathrm{Vs} \mathrm{I}-2)$ & $\mathrm{T} 2(0 \vee \mathrm{s} 3-4)$ & $\mathrm{T} 3\left(1-2 V_{s} 3-4\right)$ \\
\hline \multicolumn{2}{|l|}{$T$} & 3.96 & 4.02 & 0.26 \\
\hline \multirow{2}{*}{ ANOVA } & $\mathrm{F}$ & & 9.2 & \\
\hline & P-value & & 0.002 & \\
\hline
\end{tabular}

From table (XI) it clear that the mean value of total needed dose of misoprostol in P1\&2 was significantly lower than that in $\mathrm{PO}$, the mean value of total needed dose of misoprostol in $\mathrm{P} 3 \& \mathrm{P} 4$ was significantly lower thant that in $\mathrm{PO}$ and there was no significant difference between the mean value of total needed dose of misoprostol in P1\&P2.

Table XII : The difference in mean values of parity, induction contraction interval, induction delivey interval and total needed doses of misoprostol (in micrograms) between cases in the 2 nd and cases in the 3rd trimesters IUFD.

\begin{tabular}{|c|c|c|c|c|c|}
\hline & & Range & Mean $\pm S D$ & $\mathbf{t}$ & P-value \\
\hline Parity & $\begin{array}{l}2^{\text {nd }} \text { trimester } \\
3^{\text {rd }} \text { trimester }\end{array}$ & $\begin{array}{l}0-4 \\
0-4\end{array}$ & $\begin{array}{l}1.900 \pm 1.619 \\
2.150 \pm 1.565\end{array}$ & -0.50 & 0.622 \\
\hline $\begin{array}{l}\text { Induction Contraction } \\
\text { Interva! }\end{array}$ & $\begin{array}{l}2^{\text {nd }} \text { trimester } \\
3^{\text {rd }} \text { lrimester }\end{array}$ & $\begin{array}{c}10-24 \\
5-13 \\
\end{array}$ & $\begin{array}{c}15.3 \pm 5.37 \\
8.950 \pm 2.625 \\
\end{array}$ & 4.75 & $<0.01$ \\
\hline $\begin{array}{l}\text { Induction Delivery } \\
\text { Interval }\end{array}$ & $\begin{array}{l}2^{\text {nd }} \text { trimester } \\
3^{\text {rd }} \text { trimester }\end{array}$ & $\begin{array}{l}22-45 \\
16-28\end{array}$ & $\begin{array}{c}30 \pm 8.25 \\
21.050 \pm 3.634\end{array}$ & 4.26 & $<0.01$ \\
\hline $\begin{array}{l}\text { Total dose } \\
\text { (in } \mu \mathrm{g})\end{array}$ & $\begin{array}{l}2^{\text {nd }} \text { trimester } \\
3^{\text {rd }} \text { trimester }\end{array}$ & $\begin{array}{l}150-275 \\
100-175\end{array}$ & $\begin{array}{l}166.3 \pm 57.5 \\
120 \pm 28.79\end{array}$ & $3.51^{*}$ & $<0.01$ \\
\hline
\end{tabular}

Table (XII) shows that the mean value of induction contraction interval in cases of 2nd trimester IUFD was significnntly higher than that in cases of 3rd trimester IUFD ( $P<0.01)$. The mean of induction delivery interval in cases of 2nd trimester IUFD was also, significantly higher than that in cases of 3rd trimester IUFD. The mean value of total required doses of misoprostol in cases of 2nd trimester lUFD was significantly higher than that in cases of 3rd trimester IUFD.

Table XIII : The difference between cases of 2 nd and 3rd trimesters IUFD as regards the need for oxytocin augmentation.

\begin{tabular}{|l|c|c|c|c|}
\hline \multirow{2}{*}{} & \multicolumn{2}{|c|}{ 2nd trimester IUFD } & \multicolumn{2}{c|}{ 3rd trimester IUFD } \\
\cline { 2 - 5 } & $\mathrm{N}$ & $\%$ & $\mathrm{~N}$ & $\%$ \\
\hline Cases in need for oxytocin augmentation & 18 & 90 & 11 & 55 \\
\hline cases not in need for oxytocin augmentation & 2 & 10 & 9 & 45 \\
\hline \multirow{2}{*}{ Chi-square } & $\mathrm{X}^{2}$ & \multicolumn{4}{|c|}{6.14} \\
\cline { 2 - 5 } & P-value & \multicolumn{3}{|c|}{$<0.05$} \\
\hline
\end{tabular}


Table IVX : The difference between cases of 2 nd and 3rd trimesters IUFD as regards of need for surgical interference for retained placenta.

\begin{tabular}{|l|c|c|c|c|}
\hline \multirow{2}{*}{} & \multicolumn{2}{|c|}{ 2nd trimester IUFD } & \multicolumn{2}{c|}{ 3rd trimester IUFD } \\
\cline { 2 - 5 } & $\mathbf{N}$ & $\%$ & $\mathbf{N}$ & $\%$ \\
\hline Cases in need for surgical interference & 6 & 30 & 1 & 5 \\
\hline Cases not in need for surgical interference & 14 & 70 & 19 & 95 \\
\hline \multirow{2}{*}{ Chi-square } & $\mathrm{X}^{2}$ & \multicolumn{3}{|c|}{4.33} \\
\cline { 2 - 5 } & P-value & \multicolumn{4}{|c}{$<0.05$} \\
\hline
\end{tabular}

From table (IVX) it is clear that: the need for surgical interference because of retaincd placenta was significantly higher in 2nd trimester IUFD than that in: 3rd trimester women with IUFD.

Table VX : The rate of occurrence of side effects durign induction.

\begin{tabular}{|l|l|c|c|c|c|}
\hline \multirow{2}{*}{} & \multicolumn{2}{|c|}{ 2nd trimester IUFD } & \multicolumn{2}{c|}{ 3rd trimester IUFD } \\
\cline { 2 - 6 } & $\mathbf{N}$ & $\%$ & $\mathbf{N}$ & $\%$ \\
\hline \multirow{2}{*}{ Occurrence of isde effects } & 6 & 30 & 0 & 0 \\
\hline Absence of side effects & 14 & 70 & 20 & 100 \\
\hline \multirow{2}{*}{ Chi-square } & $\mathrm{X}^{2}$ & \multicolumn{3}{|c}{$7.1^{*}$} \\
\cline { 2 - 5 } & P-value & \multicolumn{3}{|c|}{$\mathrm{P}<0.01$} \\
\hline
\end{tabular}

Table VXI : The rate of induction success in 2nd versus 3rd trimesters IUFD.

\begin{tabular}{|c|l|c|c|c|c|}
\hline \multirow{5}{*}{$\begin{array}{c}\text { Needed dose of } \\
\text { misoprostal }\end{array}$} & \multicolumn{2}{c|}{ 2nd trimester IUFD } & \multicolumn{2}{c|}{ 3rd trimester IUFD } \\
\cline { 2 - 6 } & \multicolumn{1}{|c|}{$\mathbf{N}$} & $\%$ & $\mathbf{N}$ & $\%$ \\
\hline \multirow{5}{*}{ Success } & 100 & 0 & 0 & 4 & 20 \\
\cline { 2 - 6 } & 125 & 0 & 0 & 7 & 35 \\
\cline { 2 - 6 } & 150 & 9 & 45 & 7 & 35 \\
\cline { 2 - 6 } & Total of success & 9 & 45 & 18 & 90 \\
\hline \multirow{5}{*}{ Failure } & 175 & 3 & 15 & 2 & 10 \\
\cline { 2 - 6 } & 200 & 2 & 10 & 0 & 0 \\
\cline { 2 - 6 } & 225 & 1 & 5 & 0 & 0 \\
\cline { 2 - 6 } & 250 & 3 & 15 & 0 & 0 \\
\cline { 2 - 6 } & 275 & 2 & 10 & 0 & 0 \\
\cline { 2 - 6 } & Total of failure & 11 & 55 & 2 & 10 \\
\hline
\end{tabular}




\section{DISCUSSION}

Misoprostol is absorbed rapidly when administered orally, vaginally, rectally or intracervically. The vaginal route is advantagcous because peak levels are reached slowly and sustained for long and this is associated with fewer side effects ${ }^{(8,9)}$.

After oral administration of misoprostol, the plasma concentration begins rising quickly, 2 minutes after administration, reaching a peak serum level between 12.5 and 60 minutes and declining steeply at 120 minutes, after administration. After vaginal administration of misoprostol, the plasma concentration begins rising gradually reaching a peak scrum level between 60 and 120 minutes and declining slowly at 240 minutes after administration $(10,11)$. Clinical trials indicate that the optimal dose and dosing interval is $25 \mu \mathrm{g}$ intravaginally every 4 to 6 hours. Higher doses or shorter dosing intervals are associated with a higher incidence of side effects, especially hyperstimulation syndrome $e^{(6,12)}$. These data support the rationale of misoprostol application at 4-h used in our study.

In the current investigation, we found a significant negative correlation between parity and induction contraction interval. There was a significant negative correlation between parity and induction delivery interval. Also, there was a highly significant negative correlation between parity and total needed dose of misoprostol.

on the contrary to our above mentioned results, Auxiliadora de Aquino and Cecatti ${ }^{(13)}$ found no significant differences between the groups concerning conditions for labor induction, age, parity, race, marital status, family income, initial Bishop Index and number of prenatal vistis.

We found highly significant negative correlation between gestational age and induction contraction interval; between gestational age and induction delivery interval and between gestational age and total needed dose of misoprostol.

Nakintu ${ }^{(14)}$ studied 120 women at 18 to 40 weeks of pregnancy complicated with IUFD, where their pregnancies were terminated with either vaginal misoprostol or intravenous infusion of oxytocin. In the misoprostol group, the starting dose was $50 \mu \mathrm{g}$ and the dose was doubled every 6 hours till effective contractions were achieved. If delivery was no established within 48 hours of the start of induction, this was regarded as "failed induction" and the drug administration stopped. The success rate within 48 hours of induction was $100 \%$ in the misoprostol group and $96.7 \%$ in oxytocin group. The mean induction 10 delivery time was significantly longer in the oxytocin group compared with the misoprostol group (23.3 versus 12.4 hours; $p=0.004$ ). The earlier the gestational age, the longer was the induction to delivery interval. Women with intact membranes had induction to delivery interval of 27.9 hours in the oxytocin group and 14.7 hours in the misoprostol group ( $\mathrm{p}=0.002$ ). the induction to delivery time in cases with Bishop's score $<6$ was 29.8 hours in the oxytocin group and 15.9 hours in the misoprostol group $(p=0.001)$. The corresponding values for Bishop's scores $>6$ were 10 and 7.9 hours respectively $(p=0.6)$. The majority of patients $(62 \%)$ in the misoprostol group required less than one tablet (200 $\mu \mathrm{g}$ ) for successful induction and the maximum dose of $750 \mu \mathrm{g}$ was needed by only 3 patients $(6 \%)$.

The side effects were mainly nausea, vomiting, shivering and pyrexia especially with misoprostol but these were transient. There were no cases of ruptured uterus in both groups. Retained placenta occurred in only $3.3 \%$ of the patients in the misoprostol group.

The present investigation shows that the mean value of induction contraction interval in cases of 2 nd and 3rd trimesters IUFD in primipara and second para was significantly lower than that in nulliparae. Similarly, the mean of induction contraction interval in third and fourth para was significantly lower than that in nulliparae. There was no significant difference between the mean of induction contraction interval in primipara 
second para and that in third and fourh para. We found also, that the mean value of induction contraction interval in cases of 2nd trimester IUFD $(15.3 \pm 5.37$ hours) was significantly higher than that in cases of 3rd trimester IUFD ( $8.95 \pm 2.625$ horus).

This agrees with the reports of Nakintu ${ }^{(14)}$ who stated that the earlier the gestational age, the longer was the induction to delivery interval.

Bugalho and his colleagues ${ }^{(15)}$ found that the average induction-to-delivery interval was 14.8 hours in vomen with late IUFD where their pregnancies were terminated with vaginal misoprostol.

Our current study shows that the mean value of induction delivery interval period in cases of 2 nd and 3rd trimesters IUFD in nulliparae was significantly higher than the corresponding values in women with previous history of childbirth. On the contrary, another study ${ }^{(14)}$ reported shorter duration than that found in the current investigation. The difference may be due to use of much lower doses and exclusion of cases with Bishop Score $\geq 5$ and cases with ruptured membranes from the current study. $80 \%$ of patients required less than $200 \mu \mathrm{g}$ to be delivered and the maximum dose of $275 \mu \mathrm{g}$ was needed by only 2 patients $(10 \%)$. The induction to delivery time was $13.5 \pm 8.3$ hours with vaginal misoprostol ${ }^{(16)}$.

Our results differ from those who studied 72 women at 18 to 40 weeks of pregnancy complicated with IUFD, without abdominal scars and not in labour. Their pregnancies were terminated with 100 $\mu \mathrm{g}$ of intravaginal misoprostol which was repeated every 12 hours for up to 48 hours. The mean time from induction to delivery was $12.6 \pm 9.1$ hours. $92 \%$ of patients were delivered within the first 24 hours and only 6 patients (8\%) delivered between 24 and 48 hours, at the end of which all patients had been delivered. There was no significant difference $(P>0.05)$ in the mean time from induction to delivery - either with gestational age or with parity ${ }^{(17)}$.

The existing study revealed that the mean values of total required dose of misoprostol in cases of 2 nd and 3rd trimesters IUFD in nullipara was significantly higher than that required in parous women. Increased parity had no significant effect on the mean value of the required dose. The average of total required doses of misoprostol in cases of 2nd trimester IUFD $(166.3 \pm 57.5 \mu \mathrm{g})$ was significantly higher than that in cases of 3rd trimester IUFD $(120 \pm 28.79 \mu \mathrm{g})$.

We found that the need for oxytocin augmentation was significantly higher in cases of 2 nd trimester IUFD (90\% of cases) than that in 3rd trimester IUFD (55\% of cases). Nyende (16) found that $20 \%$ of his cases required oxytocin augmentation to complete the induction of labour.

The need for surgical interference for retained placenta was significantly higher in cases of 2nd trimester IUFD ( $30 \%$ of cases).

The success rate in cases of 2 nd trimester IUFD was $45 \%$ (we considered successful when induction delivery interval was less than 24 hours). Regarding of cases of the third trimester IUFD, the success rate was $90 \%$. This resull agrees with that of many other authors (18-19) who reported that with misoprostol administration, the vast majority of women with IUFD will deliver gvaginally within 24-hours. Nakintu (14) studied 120 women at 18 to 40 weeks of pregnancy complicated with IUFD. He found that the success rate of induction within 48 hours of induction was 100\% which is identical to our results.

Last but not least, we conclude that Vagiprost ${ }^{\circledR}$ is a very effective drug for termination of pregnancy in cases of IUFD; its effects increase in direct proportion with parity and duration of pregnancy.

\section{REFERENCES}

1.Kochenour NK. Management of fetal demise. Clin Obstet Gynecol. 1987; 30: 322.

2. Chittacharoen A, Herabutya $Y$ and Punyavachira P. A randomized trial of oral and vaginal misoprostol to manage delivery in cases of fetal death. Obstet Gynecol. 2003; 101: 70.

3. Arias F. Pharmacology of oxytocin and prostaglandins. Clin Obstet Gynecol. 2000; 43(3): 453. 
4. Hale RW and Zinberg S. (2001). Use of Misoprostol in Pregnancy. New England Journal of Medicine 2001: 344: 59-60.

5. American College of Obstctricians and Gynecologists. Committee on Obstetric Practice. Response to Searle's drug warning on misoprostol. Commiltec opinion. No: 248. Washington, DC, USA. ACOG; 2000.

6. Goldberg AB, Greenberg MB and Darney PD. Misoprostol and pregnancy. $N$ Eng J Med. 2001; $344: 38$.

7. Gollschall D, Borgida A, Mihalek J, Sauer F and Rodis I. A. randomized clinical trial comparing misoprostol with prostaglandin E2 gel for preinduction cervical ripening. Am J. Obstet Gynccol. 1997; 177: 1067.

8. Jing S. Use of misoprostol in Obstetrics and Gynaccology. Obstel Gynecol Surv. 2000; 55(8): 503.

9. Neai SW, Chan YM, Lam SW and Lao TT. Labour characteristics and uterine activity: misoprostol compared with oxytocin in women at term with prelabour rupture of membrances. $\mathrm{Br} J$ Obstet Gynaccol. 2000; 107: 222.

10. Zieman $M$, Fong SK, Benowitz $N$ and Darney $P$. Absorption kinelics of misoprostol with oral and vaginal administration. Obstet Gynecol. 1997; 90: 88.

11. Bygdeman M. Pharmacokinetics of prostaglandins. Best Pract Res. Clin Obstet Gynaecol. 2003; 17(5): 707.

12. Norwitz E Robisson J and Repke J. Labor and delivery. In: Gabbe SG, Niebyl JR, and Simpson JL (eds.): Obstetrics: normal and problem pregnancies 4th edition, New York, Churchill Livingstone. 2002; p. 353-394.

13. Auxiliadora de Aquino $\mathrm{MM}$ and Cecattj JG. Misoprostol versus oxytocin for labor induction in term and post-tem pregnancy: randomized controlled trial, Sao Paulo Med. J. 2003; 121: 3.

14. Nakintu N. A comparative study of vaginal misoprostol and intravenous oxytocin for induction of labor in women with intrauterine fetal death in Mulago Hospital, Uganda. African Health Sciences. $2001 ; 1(2): 55$.

15. Bugalho A, Bique C, Machungo $F$ and Bergstrom $S$. $V$ aginal misoprostol as an alternative to oxytocin for induction of labor in women with late fetal death. Acta Obstet Gynecol Scand. 1995; 74(3); 194.

16. 16-Nyende L. Comparison of vaginal and oral misoprostol, for the induction of laboru in women with intra-uterine foetal death. East African Medical Journal. 2004; 81(4): 179-182.

17. Bugalho A, Bique C, Machungo $F$ and Faundes A. Induction of labor with intravaginal misoprostol in intrauterine fetal death. Am J Obstet Gynecol. 1994; 171(2): 538 .

18. Ngaj SW, Tang OS and Ho PC. Prastaglandins for induction of second-trimester termination and intrauterine death. Bes Pract Res Clin Obstet Gynaecol. 2003; 17(5): 765-775.

19. Fawole AO, Adenkunie AI, Sotiloye OS, Arowojulu $A O$ and Otolorin EO. Experience with intravaginal misoprostol in the management of intrauterine fetal death. Afr J Med Sci. 2004; 33: 105-108. 